\title{
Exploring Gender Socialization on African Political System and Women's Participation
}

\author{
Andrew Enaifoghe \\ University of Zululand, KwaDlangezwa, KwaZulu-Natal, South Africa \\ andyransey@gmail.com
}

\begin{abstract}
This study explored the role of gender plays and the participation impacts of women on African politics, the religion and socio-cultural factors responsible for the underrepresentation of women through socialization in Africa. Obviously, past research has demonstrated that fundamentalist religious beliefs and affiliations are related to preservationist gender demeanours or attitude. This idea not only impacts gender gaps in political participation in cross-national examinations by belligerence that women's portrayal ought to be measured in an unexpected way or differently. Utilizing Fundamentalism and Modernization Theories, this paper shows that long haul impacts of women's representation are more indispensable than short-term measures in understanding gender gap in a mixture of political exercises. The timeframe since women have accessed the political framework discloses the gender gap to a more noteworthy degree than the presence of women in the governing body and cabinet at one point in time. Findings demonstrate that the suppositions of earlier work on women representation and political conduct or attitude may stretch out beyond Africa it also finds that gender grouping has in many ways impacted the low participation of women in African political system through socialization. At last, this study shows that the kind of political exercises matter and the implementation of policies that encourage give women level play ground to participate in politics while breaking down the impact of gender socialization as of the factors for women's representation in legislative issues crosswise over Africa. A qualitative approach was used in this study alongside with empirical investigation.
\end{abstract}

Keywords: Participation, representation, gender gaps, politics, socialization, media, fundamentalism

\section{Introduction}

The process whereby individuals are informed on or about their behaviours, norms and customs which is associated, with their assigned sex or gender, which is usually during their early life of childhood development is regarded as gender socialization. Individuals within a given society are taught how to behave socially in line with their assigned gender that is given to them from birth, based on sex phenotype is viewed as gender socialization (Boundless, 2017). It is believed today that most gender manifestation differences are as a result or attributed to the differences in socialization, rather than biological factors or genetics. Many people tend to typically view and group socialization into masculine-feminine binary, while there are others whose gender identity differ or does not align with their assigned sex or gender as given to them from birth, this means that the gender binary does not completely apply in this case. The key terms of the gender socialization process include educating and instructing males and females as for what norms, behaviours, values and beliefs of the society or culture where they belong. Gender socialization is differentiating between the roles of men and the roles of women which is acceptable within a society (Boundless, 2017). The preparation for gender socialization start even before a child is born into life and the society this is where people often ask the expectant mother about the sex or gender of their yet unborn child, this is regarded as the beginning of social gender categorization process which may continue throughout the existence of life.

Gender socialization simply assigns roles to an individual based on their sexual orientation with the society. However, in response to the roles typically assigned to the female gender, it tends to discriminate women from taking up the certain role of leadership as it is seen to be male's roles (in a man's world), this has adversely affected women's partaking in public function and with regards to political leadership. Women political cooperation and participation has become the open and comparable inclusion of women in political issues of government and the administration of the community where they are. This could be done by means of elective, chosen or merited positions. It implies the recognition or acknowledgement and the admiration or value attached to the obligation of all integrating women in the governing disposition of any group, state or nation. Basic leadership with the decision-making process becomes beneficial to a nation when it echoes or reflects the synergistic contributions from all individuals from the communities without discrimination or separation of a particular gender (New Tactics, 2015). It is essential to have both amount and quality in the 
women gender partaking in administration with men folks. Studies have uncovered that increased women's involvement and true participation.

In political issues of states has brought about greater economic advantage, increased collaboration crosswise over party divisions and further maintainable compromise (New Tactics, 2015). It is essential to bring women's commitment up in governmental issues by cultivating and educating their consciousness of chances accessible, building certainty and aptitudes. Focusing on women at the grass root level has achieved impactful outcomes as it witnessed in Saudi Arabia, where women are now being considered for the first time to run as candidates in the local elections. However, NGOs have been an exceptionally solid main impetus behind the expansion in the number of women in the political field by connecting nearby movements campaigns to worldwide activities and patterns. Through diverse conventions of the United Nations, governments have embraced and have set the base for all-inclusive strategies, for example, the Beijing Policy forum for Action, International Covenant on Civil and Political Rights, Convention on the Elimination of all types of Discrimination against Women, and more so, with the territorial mechanisms for gender equality. At the local and group level, the right to the highest level of government, women are regularly inadequately underrepresented in management positions. They are left without a voice in basic leadership with regards to the decision-making process and disregarded as an electorate. Women hold just 22 percent of national parliamentary positions universally (New Tactics, 2015).

This implies ladies are underrepresented in all facets of the political procedure frequently this is because of some social-cultural obstructions, the absence of training or framing and economic resources for women's political arranging, ways of life and problematic financial difficulties. The 1998 National Action Plan for the Promotion and Protection of Human Rights (NAP) compacts with the political privileges of women. VyasDoorgapersad, (2014) highlighted that the development of NAP is as a result of the Vienna Declaration and Program of Action 1993. In South Africa, the year 1995 marked the endorsement of CEDAW -" Convention on the Elimination of all forms of Discrimination Against Women, it was however adopted in 1979 by the United Nations general assembly, it is described as an international bill of rights for women, that was instituted on the $3^{\text {rd }}$ of September 1981, and was ratified by 189 states." Following this South Africa took after it by the foundation of the Commission on Gender Equality that is a basic piece of the National Machinery for Gender Equality - to create and direct instructive projects, assess charges identified with the status of women, and consider proposals and suggestions concerning the advancement of gender fairness; and the Office on the Status of Women - to propel the national strategy on sex uniformity, to lead examine on gender issues, and in charge of viable execution of strategies on gender and projects at the national, common and nearby circles of government.

The Office of the Status of Women built up a National Framework for Women's Empowerment and Gender Equality, embraced in 2000 keeping in mind the end goal to fortify the voices of women in political leadership at the three circles of government (Legislature, Executive and Judiciary). It additionally focuses on the need to build up a local government apparatus to propel strengthening of ladies and gender uniformity. The South African Local Government Association (SALGA) in the organization with the Department of Provincial Affairs and Local Government (DPLG) received, which basically focused on the need to define and execute systems to improve women portrayal support, and participation in local government as far as enactment by the Women's Caucus. The Local Government White Paper (1998), with reference to gender orientation, expresses that "local government is interestingly set to examine and comprehend control elements within a group, and guarantee that the individuals who have a tendency to be barred and minimized can wind up dynamic and equivalent members in group and the change of the settlements where they live". Under the idea of "Formative Local Government", the White Paper acknowledges that "there are numerous snags to the equivalent and powerful support of women, for example, social qualities and standards, and also functional issues, for example, the absence of transport, family unit obligations, individual security and safety, and so on." It accordingly, looks for the methodologies to improve the support involvement of women at the local government level. 


\section{Literature Review}

Consideration of the Fundamentalist and Modernization Theories: The utmost rudimentary utilization of the word called the "fundamentalism". The fundamentalists are basically the "American Protestants" who through an aggressor need to protect their "religion against the strikes of modern", standard culture; the foremost weapon is the emphasis and accentuation on the inerrancy or request of the holy written work of the past, known as the book of scriptures (the holy bible or holy book, or the bible). Hawley (1994) portrays fundamentalism to be an anti-modernist in nature. While fundamentalists don't expel the inventive advances of modem life, they do portray themselves as opposed to particular parts of modem culture. These consolidate intelligent naturalism higher criticism of the Bible saw changes in moral regards or qualities. Fundamentalists don't just pull back themselves from particular examples in modem culture they submit themselves to battle against those examples. Hawley says for fundamentalists, singular experience and Biblical inerrancy exhibit reality of the Christian tradition notwithstanding modem question. Fundamentalism makes straight with social and fiscal issues that exist in contemporary culture. Fundamentalism is a pull of thoughtfulness for an earlier way of life. Hawley further acknowledged that the way of life in the early period was not the life of Jesus and that of the early Christianity, as it is consistently depicted, but the appreciated variation of home and gathering life in the private groups of communities, in America in the nineteenth century. Lechner (1993), states that the fundamentalists consider development to be a ruinous or catastrophic power. However, the modem society puts little enormity on religious traditions, and influences a landing to sureness to compel. This view on fundamentalism according to Lechner is a kind of anti-mode mist whose objective means to reinstate vital demand in view of a blessed custom.

Furthermore, the fundamentalist uses the writing of the Bible as a book to their advantage in the fundamentalist conflict to support their argument against advancement and modernization. Moreover, Chalfant, Beckley, and Palmer (1994) deliberated on the fundamentalist/mode mist discourse as the impact of science and the judiciousness use of uncertainty which began to plague insightful life, fundamentalists wound up isolated from other powerful Protestants. Researchers pushed fundamentalists to register their claim against urbanization and the influence science has on the Biblical elements. Ammerman (1987) explains Protestant fundamentalists as one related with dynamic protection from progressivism, secularism, and communism. Therefore, as one of the rule fragments of the fundamentalist conviction structure is inerrancy. The steadfast confidence' in an inerrant of the book of Bible empowers fundamentalists to rely on the Bible and it can be trusted to give a correct explanation of significant quality and religion, and furthermore science and history. This religion believes in the Bible which warrants them to oppose the development. Critics in the era of advancement believed that the last stage may come where reason and rationale will have the capacity to supplant religion. The creating sense among fundamentalists was that in the event that they didn't go to willow for the norms, they would not simply misplay the position of religion in their lives. This will in the general public might be lost for time everlasting (Ammerman, 1987). In case they didn't confront researchers suspicious of the Bible and an organization who took after this insightful illustration, they won't have another period of devotees. Fundamentalists believed they should end up unique in saving their conviction system and in reality saving the nation.

\section{Materials and Methods}

This study adopted a qualitative method which basically allows researchers to study and consult, then make sense of written materials which may be available either in public or private domain (Mogalakwe, 2006). The above definitions recommend that researchers determine the relevance of the documents that they consult on the basis of their significance to the study. Furthermore, Dey (2005, p.105) argues that in documented analysis, the criteria for selecting documents, or for focusing on particular extracts, should reflect the issues on which the researcher is seeking evidence. Furthermore, to add credence to this study, the researcher further utilized empirical experimentation through observation with the view to understand the feeling of women participating in politics and their access to opportunities. This is thereby resulting to the low percentage of women in a position of governance in selected countries Africa, this method made it possible for the researchers to explore the various factors that impacts on the inadequate representation of women in African politics as a result of gender discrimination, power play and socialization. Africa is culturally diverse 
and numerous event including socializations could be said to impact the low inclusion of women in political matters in Africa.

\section{The Gender Role in Socialization}

In order to understand gender's role in socialization, we need to first have an insight into the part religion plays in gender part to socialization and support to participate in political issues. It is first imperative to look at a bit of the vital suppositions about gender socialization. Brown (1994) trusts gender orientation positions are the most basic building squares of social affiliation. The part gender orientation put among the social, the capabilities for children to learn at first, and remain the basis for the length of one's life. In making cut-off points and concentrating on the complexities among people, kids, and furthermore adults, feel secure and prepared to manage their roles for the duration of regular daily existence. He further says holding women under the control of men impacts the world to have all the earmarks of being all the more composed and understandable. It isn't gorgeous then that such a broad sum of the fundamentalist arrangement fixates on portraying the place of men and women in the general public. McGuire (1981) discusses some major sexual orientation roles feelings in our overall population the implications of masculinity and sophistication are socially established. In view of these definitions, a get-together makes and stimulates certain differentiations among people. McGuire (p. 112) constructs, in socialization, male and females are told that their socially delegated sexual orientation roles to the social gathering's wants of practices, demeanours, and motivations "legitimate" to male and females. By and large, religion has been a champion among the most critical wellsprings of these social implications of the roles women plays; and then religion has become an effective legitimation of those capabilities. Religions have been viewed as having a critical effect in taking in one's gender overview role of conduct. McMurry (1978) spearheaded a study considering an association among religion and sexual orientation role presentations. In perspective of a 1964 NORC test, the revelations prescribe a significant religious effect on gender parts perspectives.

Traditionalism in this examination is described as a perspective perfect to the likelihood that women's lives should be essentially home-and family-engaged. Religion propels a conviction framework which sees the standard family structure as a noteworthy part of the customary and great demand, then possibly powerfully designated. What was legitimate for sexual orientation position in the initiative in 1964 may conceivably applicable in the 1990s. According to another scholar, Smith (1974), who conducted research and analysed 106 schools understudies the measures of acclimation to standard gender views, the identity with sexual orientation, and their religious presentation. Smith uses McMurry's (1978) investigation as a foundation for his examination. General disclosures reinforce the factors of socialization that ultimately affect sexual orientation character and disposition towards political authority. Religious socialization increments have strengthened distinctive wellsprings of the sexual orientation of socialization. Christian religious and African religious practices with its guideline reinforce the upkeep of traditional parts and convey this as fundamental conducts for men and women alike.

Furthermore, Smith submitted that for the women gender, there are traditionalism intensifications with development in religious commitment. The people who are likely more religious may reliably be required to play their suggested parts further genuinely. A constructive alliance partner religiosity to traditionalism for the two sexes was found. Smith's examination offers assistance for McMurry's previous disclosures of religious effect on sexual orientation position acquaintance enduring or continues to apply up to date. The socialization of gender into religion and the role of socialization, to one's sexual orientation encompass regular effects. The connexion may be considered regardless, as this believes it is basic to consider the impacts religious has on gender parts not simply in light of the way that the composition shows reinforce for a religious sway on customary feelings. However, as a technique for surveying the factors influencing sexual orientation awkwardness in African political authority which put the females gender on the low for representation. Religious choice isn't just an open method; it expects a section in socialization and impacts the unequal position of people.

Fundamentalist Theory and the Gender Attitudes: At the individual level with the fundamentalist groups, it began to a great extent out of the nineteenth century with what is called "Holiness and Pentecostal" developments (Ammerman 1987; Woodberry and Smith 1998). The fundamentalists have a tendency to 
contradict the development of common impact in the public arena (Hawley and Proud foot 1994). They additionally have a tendency to have confidence "in the inerrancy of the holy book (the Bible)", individual deliverance or salvation, which is the pre-millennial and coming back of Jesus Christ, and the outreaching necessity to change over others (Ammerman 1987; Woodberry and Smith 1998). The Fundamentalist Protestants support customary roles of sexual orientation states of mind, in faithfulness and in fulfilment of the scriptural entries that depict men as pioneers and leaders, however women as mere adherents or believers (Ammerman 1987; Bendroth 1993). The conventional chain of command instructed by fundamentalist temples is from God to man and from man to woman, with women's parts characterized as that of assistant and mother (Kosmin and Lachman 1993). Appropriately, fundamentalists have a tendency to contradict current, adjusted gender roles wherein ladies have entered the paid workforce, looked for more libertarian divisions of family unit work and championed themselves all the more straightforwardly in conjugal basic leadership with regards to decision-making (Brown 1994; Kosmin and Lachman 1993). Indeed, even the most punctual studies of sexual orientation states of mind or attitudes noticed the relationship of religious categories and convictions with moderate gender demeanours (Mason and Bumpass 1975).

Utilizing 1972-84 GSS information, Hertel and Hughes (1987) discovered white Protestant fundamentalists hold the utmost traditionalist states of mind or attitudes on ladies' home, exertion, and governmental roles. Baptists, Catholics, Methodists, Lutherans, Presbyterians, Episcopalians, Jews, and those announcing no religious association indicated continuously more liberal sexual orientation attitudes. The traditionalist fundamentalist impact stayed solid subsequent to controlling for age, wage, training, and locale. Hoffmann and Miller (1997) report from their longitudinal examination of 1972-94 GSS information that while moderate Protestant (Southern Baptists, Evangelicals, Fundamentalist, Nazarenes, Pentecostals, Church of Christ) bolster for libertarian gender parts has expanded, this gathering is still among the most traditionalist or conservative. Utilizing 1982-91 GSS information, Gay, Ellison, and Powers (1993) locate that white Southern Baptists and other fundamentalist and outreaching individuals report the most moderate states of mind on genius family issues, for example, gender roles, fetus removal or abortion, and sexuality. Once more, these impacts stay in the wake of controlling for a few individual-level factors. In any case, Gay, Ellison, and Powers (1993) documented some interior heterogeneity on sexual orientation role attitudes in the traditionalist Protestant divisions, driving specialists to reconsider suppositions of a solid fundamentalist/outreaching gathering. They propose that issues of female business and family unit, basic leadership with decision-making are "more nuanced and consulted than beforehand perceived". The solid connection amongst fundamentalism and moderate gender attitude has likewise been archived by deliberates utilizing more particular, unrepresentative examples (Brinkerhoff and Mackie 1984: Martin et al., 1980; Thornton, Alwin and Camburn 1983; Thornton and Freedman 1979) and by studies in estimating fundamentalism as individual convictions (Brinkerhoff and MacKie 1984).

Consequently, inhabitants in zones with greater extents of fundamentalists may have a more prominent presentation to media projects and notices, school educational program, instructor understudy associations, and legitimate/legal frameworks that underline fundamentalist motivated traditionalist gender dispositions. The social standards legitimized by these establishments would affect fundamentalists and nonfundamentalists alike. Also, people wishing to challenge existing moderate belief systems may wind up battling against a fundamentalist voting public that could assemble rapidly and forcefully through their congregation assemblages or bigger Christian Right gatherings, for example, the Moral Majority or the Southern Baptist Convention (Regnerus, Sikkink and Smith 1999). In this way, the extent of fundamentalists in a state could influence institutional help for moderate belief systems, as well as their progressing protection. Finally, people might be affected by their immediate perceptions of the social structures encompassing them. Given the prohibitive parts for women recommended by fundamentalist principle, one would expect that in more fundamentalist zones women would involve less noticeable, open, legitimate positions. Managers would be more hesitant to advance women, and maybe women would be more hesitant to look for open places of a specialist. Therefore, the general state population - both fundamentalist and nonfundamentalist - would be more averse to watch women as political pioneers or leaders, CEOs, news enthusiasts, columnists, principals, ministers, and so forth. People who are not educated directly by fundamentalist belief system about suitable gender roles could at present decipher this nonappearance of 
ladies in intense positions as a characteristic event and along these lines reproduce comparable moderate sexual orientation dispositions.

The hypothetical and observational ramifications of completely reporting relevant impacts on sexual orientation attitudes are broad for the sociologies or the social sciences. To add to the literature reviewed, it is imperative to point out the role media plays in gender socialization, there is declining political participation of the youth in western society today. This has caused prevalent concerns of the true wellbeing of democracy in the future. The role media used in the formation of political attitudes among people and political socialization. The influence of exposure to media and entertainment content has impacted on political trust. Furthermore, the impact of the political and educational system on political attitude formation and civic engagement of people particularly the female gender has influence women's low participation and representation in African politics. Previous studies found that political socialization shaped political culture and influenced political participation. However, this study shows that mass media are turning into a critical agent of political socialization, as it plays host to a lot of political bodies and requires the dynamic commitment of users. In both entertainment media and news media it gives delineations that impact political socialization, for example, models of government including political leaders and national's activity. Apparently, media connections through individual are progressively essential to the procedure of political socialization. The explosion in correspondence innovations and technologies has brought about individuals less communication through vis-à-vis interaction with family and friends and loved ones, they rather engage with one another through.

Mechanical delegates or intermediaries of technologies, which incorporate web, mobile or cell phone, and other personal advanced gadgets like tablet and computer using a webcam, and more video calling on social media apps (Facebook, WhatsApp, Twitter, Instagram, and so on). The internet is viewed to be a powerful agent of political socialization because of the vast amount of political information accessible on the web and the way that individuals purposeful and in deliberate activity online stage. Individuals don't just get information about government from news locales and online journals or blogs, they likewise have the privileges of reacting to stories and discussion with others through exchanges groups. They additionally can utilize online media to effectively participate in political procedures, which incorporate election campaign. Consequently, few parents and instructors had express genuine worries and concern that socialization of youngsters through media add to a citizenry that is distanced from legislative issues and doubt government. This is on the grounds that the majority of the messages portrayed on the media about government and legislative issues are undesirable and extremely negative. Haven't said that, media has turned into convincing organizations of political learning, as youngsters invest a gigantic measure of energy being presented to TVs set, the web, computer games, and other media as opposed to cooperating with life. Media regularly depict adverse messages about political pioneers and government which may prompt the distance of the young ones especially female gender. Therefore, the argument sustained in this study that the increasing political participation of African women in political issues of government in Africa is not due to the increased education, but the implication of political socialization.

Women's Leadership and Political Participation: From the local to the global level, women's leadership and political participation are restricted. As voters, women are often underrepresented, and in addition in driving positions, regardless of whether in chose office, the common administration, the private part or the scholarly world. At the local level down to the global arena, women's administration and political interest are confined or restricted. This happens regardless of their demonstrated capacities as pioneers and drivers of change, and their entitlement to take an interest similarly in a democratic administration. Women are often faced with few snags or challenges as to taking an interest in political life. There are structural hindrances through oppressive laws foundations which still point to the confinement of women's alternatives to keep running for office (UN women, 2017). The capacity limit has created gaps which makes women improbable than men to have the training, contacts and assets expected to end up as viable leaders. As the $2011 \mathrm{UN}$ General Assembly determination on women political support notes, "Women in all aspects of the world keep on being to a great extent minimized from the political circle, frequently because of prejudicial laws, practices, mentalities and sex generalizations, low levels of education, absence of access to medical services and the unbalanced impact of poverty on women. Individual women have defeated these hindrances with incredible recognition, and frequently to the advantage of society on the loose. In any case, for women in 
general, the playing field should be level, opening open doors for all (UN women, 2017). According to Williams (1994), Gender centres around everything women and man do except for their sexuality, can change and changes after some time and as indicated by changing and erased social and communal components.

This situation is applicable to this study as women parts have changed from childbearing and overseeing family units to performing multitasks that incorporate being in professions and financial positions that society already relegated to men. Williams and Joseph (2002) additionally concur that the role of people in the public eye is likewise relegated to people based on sexual orientation as well as race, class, ethnicity and age. On the planet all over and in numerous societies men are given more power and prevalence over women (Joseph, 2002) and this situation appears to be pertinent to South Africa as the general public is as yet reeling and changing from the politically-sanctioned racial segregation time. The historical backdrop of South African women places women in all the more difficult position in light of the historical backdrop of politicallysanctioned racial segregation. Well beyond social factors that regularly segregate women, during the apartheid period, women were denied the rights to political, social and financial investment. Accordingly, change needs to happen at all segments of society so that there is a typical South African culture that is comprehensive of women. All through the apartheid battles however, females were given a stage by political gatherings, work development associations, understudies and youth arrangements and also urban associations to assume a vital part in testing politically-sanctioned racial segregation of apartheid. In the meantime, women were engaged to realise their rights to take an interest in the economy and political circle (Huffman and Pearlman, 2010). As indicated by HSRC examine (2007), the municipal government has moved toward becoming a piece of the standard approach formula for good administration. It is likewise required to offer impact to national strategies, rules, and additionally connecting with different circles of government with regards to agreeable administration. In perspective of a 1964 NORC test, the revelations prescribe a significant religious effect on gender.

\section{Figure 1 \\ Top five countries with highest proportion of women in national parliaments}

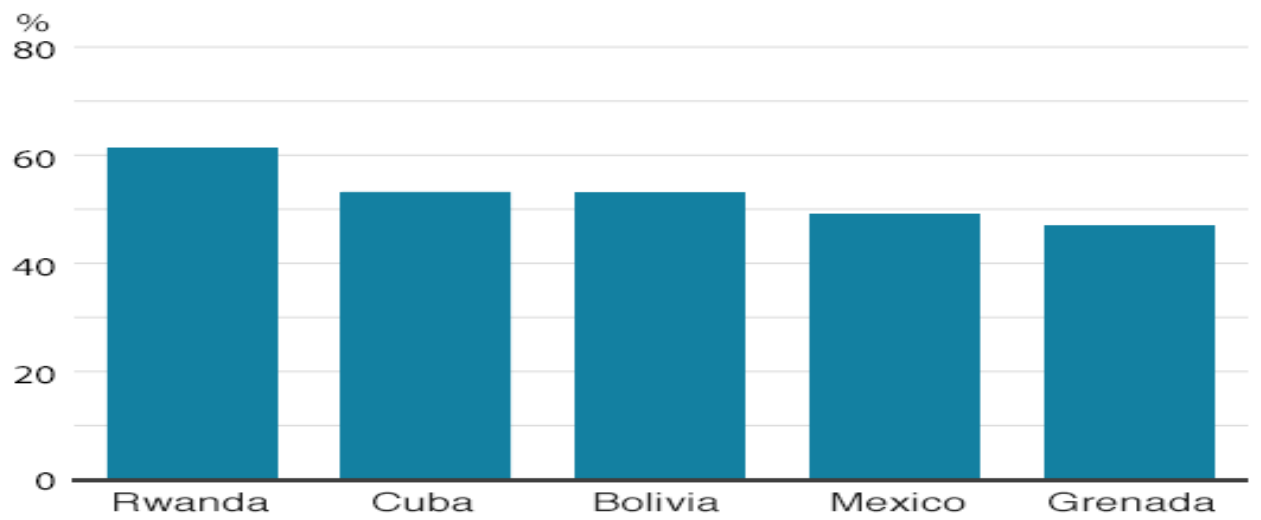

Note: Figures for lower or single house

Source: Inter-Parliamentary Union, figures up to 6 July 2018

The chart above shows the percentage of women in parliament in the top five states however, Rwanda has the highest level of women which is currently at $68 \%$ by the last quarter of 2018 . Notwithstanding detectable changes in enactment and support, ladies still face a number of difficulties. In South Africa for example, the local government is a dynamic and testing organization. Driving this basis may be somewhat demanding regardless of sexual orientation, race or ideology. The measurements on the number of women in local government preceding 1994 majority rule regulation appear to have been low because of segregation in view of race and gender in most cases. Consequently, it was relied upon for different fundamentals to help women in different structures including formulating. As much as women pioneers and leaders are assuming to work in a situation that is stable given the historical backdrop of imbalance, they were likewise constrained to convey productive support of classified complex local government partners same as their comrades in local government. The local government as a foundation exudes from decentralization of the national government 
characterized as 'the exchange of political, monetary and additionally authoritative forces to sub-national units, for the most part of government' African Institute for Community-Driven Development. This supposition is likewise shared by other scholar, for example, regions are key players in multi-sectorial coordination of the real administration transference by all advancement actors on the ground. The administration model can be exceptionally unpredictable especially in South Africa.

Ramoshaba (2005) built up a lattice, Status of Decentralization in Different Sectors, demonstrating the local administration challenges. The system outlines the characterized and indistinct parts for local government. The board to some degree diagrams the monstrous obligations of local districts wherein, elements of Provincial Departments are actualized by local governments without spending plans or being engaged with arranging to make a few inconsistencies in the way metropolitan capacity is characterized by different offices. The administration of local government like some other business setting includes settling on choice and practices that specifically influence or impact the general population who work for the organization. Ramoshaba (2005) structures a portion of the advance and difficulties confronting local government administration. He keeps up that: in spite of the considerable number of difficulties and authoritative requests sited by the administrative system, there is striking advancement made in the previous administration, a long time since benefit conveyance has been reached out to minimized community through the initiative of local regions and South Africa has been lauded globally for this extraordinary work within a brief period. The difficulties however, are more extreme in this setting contrasted with numerous foundations. Lovenduski, (2005), oppose that local government obligations incorporate huge, comprehensive regions, new official frameworks and the political arrangement of senior authorities. Sometimes districts work from an extremely frail duty base bringing about poor administration conveyance. The other assessment is the span of the population.

Barriers to Equal Participation: The commonness of customary and socio-cultural practices in most African nations have regularly been referred to as an extensive boundary or limitation for women in governmental issues. When running for political positions, numerous women confront terrorizing, provocation and once in while savagery or violence. Numerous conventional thoughts don't view governmental issues as 'women's work' and elected women have been portrayed as 'wanton' or their spouses as 'weaken' particularly in Africa, as they consider men to be the head of the family and his wife must submit to him as the husband. Tragically, this stems from the desire that women will bear children in marriage, have a substantial family and deal with their children and spouses. For women that do go into governmental issues or politics, they need to juggle satisfying both their roles at home as marital obligations and at work. Moreover, numerous families likewise confront the unforgiving reality of HIV/AIDS/AIDS and the pulverization it can bring. Harriet Harmon recounts a parliament part in Tanzania, Monica Mbega, who nurtures 16 children. Three are her own while the other 13 were the offspring of her sibling and her sister who passed away from the dreaded disease.

Such additional weights make it troublesome for women to enter into any demanding position in governmental issues or politics and afterwards to adjust their family and work lives. With the desire to wed young likewise poses as a hindrance of lower levels participation for women in Africa politics. Numerous young women quit going to class for a long time before their male partners who later makes it troublesome for them to go up against male applicants in decisions. Without access to a similar level of training, women will keep on having to battle much harder for similar openings and opportunities for a leadership position. While different nations have tried emblematic endeavours to urge women to go into legislative issues as they participate in politics, others have taken a more straightforward and controlled approach. Since the 1990s, nations over the world have begun executing quantity frameworks to guarantee the portrayal of women in legislative issues. Nonetheless, the United Nations 2004 article, "Women Break into African Politics," takes note of that around the world just about 30 nations have ordered women amounts in governmental issues and politics. The article likewise diagrams what they consider to be the three most common standard frameworks utilized as a part of Africa. Constitutional quotas- Few nations, including Burkina Faso and Uganda, have established arrangements holding seats in national parliament for ladies. Election law quotasArrangements are built into national enactment, as in Sudan. Political gathering Standards-Gatherings embrace inward standards to incorporate a specific level of women as a contender for office. 
This is the situation with the representing parties in Gender Equality in South Women and African Economic Development and Mozambique." Endeavours by universal associations and foreign nations outside Africa, for example, British chamber and United States of America ID and Gender Equality have additionally been useful in putting weight on African governments to make strides towards enhancing access for women to political support. While this has been valuable for getting government leaders to openly promise to attempt and advance women's representation, without solid strides to move down these announcements, ladies are still left to battle individually to be heard. Women's Lack of Support: While presenting quotas system, it gives a method for tending to gender unevenness imbalance in basic leadership especially with decision-making, this practice and training regularly needs supports from essential political actors or meets resistance in social orders that have solid male-centric conventions. Much like the verbal confrontation around governmental policy regarding minorities in society, those contradicted to quantity frameworks say they victimize men. The Zambia National Women's Lobby Group blames its administration for lacking political will. While the Zambian government has endorsed various worldwide instruments to advance ladies in legislative issues with regards to politics, the gathering reports, none "have been tamed." Cultural and customary works on subjecting women to male predominance have likewise upset women's advance in accomplishing sexual orientation and gender equity in legislative issues.

Women are faced with obstructions, for example, "struggle, terrorizing, negative states of mind, generalizations by society and absence of help from the electorate," takes note of the group. The UN UnderSecretary-General Ibrahim Gambari Voter in Mpumalanga, South Africa: Main obligation regarding change lies with women themselves. The Stockholm-based Institute for Democracy and Electoral Assistance (IDEA) reports that women government officials over the globe stand up to a "manly model" of legislative issues. Much of the time they need political gathering support and have no entrance to quality education or training to enter legislative issues. "Political life is sorted out for male standards and values and as a rule notwithstanding for male ways of life," notes Ms. Margaret Dongo, a Zimbabwean lawmaker. "Be that as it may, this must and will change." Zimbabwe is one of four nations in sub-Saharan Africa where the extent of female parliamentarians declined amid decisions in 2000-02. Administered shares are 'pitifully wrong," Chief Whip Douglas Gibson of the opposition Democratic Alliance in South Africa told the women's support group Gender Links. "Would you at that point say that $10 \%$ of the cricket group ought to be white and the rest dark since that is the make-up of the country? You would not, on account of not everyone would need to play cricket,' so it's a matter of choice and interests.

Unlike the decision ANC, the Democratic Alliance does not save seats for women (Wayne, 2018). Apparently, the increasing women's share of seats in parliament alone isn't an answer, as noted by the UNIFEM report. It does not ensure that they will settle on choices that advantage the greater part of women. "It can only level the odds on which women fight for equity," as reported by the UN office. Numerous variables upset selected women from advancing laws that guide women. These may incorporate breaking points on arrangement decisions parliamentarians can make, because of the advance conditions set by global financial organizations. They may likewise be controlled by "national constitutions that hamper parliamentary power in connection to the official forces of government and by political gatherings that apply solid teach over their individuals," as noted by UNIFEM. Some gender activists also contend that portions may constitute an "unattainable rank" past which women cannot go unless they participate in the extra battle. Others battle that, women who come into control under such a framework might be underestimated or seen as not politically meriting. Standards "must be a temporary arrangement not a cure for the makings of a genuine majority rule government of democracy," says Mrs. Mata Sy Diallo, previous VP of the Senegalese National Assembly.

The IDEA organization in Stockholm contends women government officials around the globe are off guard as far as budgetary assets, since women are at a larger end of the world poorest and in numerous male-centric social orders cannot possess the property and do not have economic power of their own. Regardless of such preventions, a current IDEA study considered few suggestions that women around the globe should take interest to learn the guidelines of legislative issues of politics, make conditions that enable more women to take an interest and afterwards in the long run change the standards to suit the requirements of the majority share of women. As indicated by Ms. Birgitta Dahl, a Swedish parliamentarian, 'Political gatherings, the instructive framework, non-legislative associations, exchange associations, houses of worship - all must assume liability in their own association to efficiently advance women investment, from the base up.' South 
Africa's Speaker of Parliament Frene Ginwala demands that the fundamental duty falls on women themselves. "In any general public and circumstance it is those most influenced who must realize and bring about change'. 'The individuals who are advantaged benefits from a framework that underestimates others. It is dependent upon the women", Wayne (2018).

Women's Grassroots Participation through Political System. The empowerment women in African politics with political participation and leadership, this study reveal the devices, strategies and assets utilized by people and organisations to enable women to defeat the snags keeping them from political value and fairness. The hindrances to the political participation of women distinguished in this study are the absence of open/social help or support and political gathering support, dug in conventional perspectives, absence of certainty, absence of money related means, absence of capacity building openings, absence of access to innovation, gender segregation, and division as indicated by ethnic lines, brutality, and terrorizing. Political gatherings are fundamental vehicles that could empower women's support in the political framework. The significant impediments to Women's Political Participation are conventional and social boundaries that are settled in and social standards and states of mind against women as pioneers and decision makers. It is imperative for women to have the important social and family support to beat these limiting factors. It is essential to feature the advantages of having women in basic leadership and to have local good examples to help construct local limit. To cause political gatherings, it is valuable to have compulsory standards, for example, $30 \%$ least women in initiative structures and including women wings in political gatherings.

One other great risk for women is brutality and terrorizing. This can be counteracted by having constituent sets of principles and help from non-administrative associations, for example, International Republican Institute (IRI) on good practices received to local conditions. Another obstruction identified confronting women are financial boundaries. This can be alleviated by enrolling the help of women in business and getting in kind properties like venture. Struggle financing confinements and measures to control defilement ought to be forced. Another impediment looked by women is the absence of access to information and communication advancement (ICT) which additionally been utilized to fight the female gender (women). Decidedly, ICT can be utilized to bring issues to the light of women's political activism and to sort out battles for backing, for example, Harass Map in Egypt. Political Parties and Electoral Systems: Women in parties host to be particular with party leaders with regards to behaviours and practices that avoid them from basic leadership in the decision-making process. In the US, change in the inward principles for the Democratic Party convention and structures more than 30 years back have made ready for more women's interest in participation. It is vital to have raising money, for example, Emily's List (www.emilyslist.org) particularly for women contender to empower them to centre around battling. UNDP and NDI had created a production entitled "Enabling Women for Stronger Political Parties: A manual to advance women's political investment". Obviously, women need to help each other by having solid gatherings to facilitate their interests. Obligatory standards for women have been fruitful in expanding women's interest in elections, for example, in Spain where analysts found that Spain's compulsory quotas (expecting gatherings to guarantee $40 \%$ of their possibility for nearby decisions ladies) hosted quantifiable constructive outcomes for gatherings. Lastly, the training and empowerment of women are the key to ensure that women participate in political issues in Africa. The International and local women's organizations assume a considerable part in expanding ladies' interest in legislative issues, for example, IRI's Women's Democracy Network (WDN's) Women's Political Education Forums (WPEF) has been utilized to build ladies' political commitment. Directing preparing, for example, creating media aptitudes, outlining efforts and building information of key national and nearby arrangement issues alongside long haul tutoring has helped with building ladies' certainty to go up against positions of authority starting at grassroots levels.

\section{Conclusion}

Regardless of whether the debate or discourses that more noteworthy women's political representation will bring more effective democratic governments is valid or not, most would not differ that it is imperative for women to be an essential piece of the political framework in any nation particularly in Africa. Shockingly, several women in sub-Saharan Africa confront overwhelming hindrances in entering governmental issues regards to politics and for being effective once elected. The argument in this study is that the increasing political participation of African women in political issues of government in Africa is not due to the increased 
education, but the implication from political socialization. Keeping in mind the end goal to guarantee expanded representation of women in legislative issues of African politics, it is as yet not clear what the perfect arrangement is. While established standards and deliberate gathering portions have been fruitful in Rwanda and South Africa for getting women elected into political leadership positions, a more fundamental move may be imperative too. Rwanda women hold up to $68 \%$ seats in the parliament currently. For whatever length of time that customary ideas that ladies must adhere to, 'women's work' are always presented as mothers and spouses, it will keep on being difficult for women to persuade election and to be regarded by other elected authorities. Critical advance has just been made in a wide range of African nations however balance is still exceptionally far away. UN Women's projects on administration and cooperation are guided by a background marked by worldwide duties regarding women's representation and participation in political issues. The Convention on the Elimination of All Forms of Discrimination against Women maintains women's entitlement to take an interest out in the open or public life, while the Beijing Platform for Action calls for expelling boundaries to square with cooperation.

The Millennium Development Goals measure advance towards sexual orientation uniformity to some degree by the extent of women in parliamentary seats. Towards these ends, it will be vital to give training to women political possibility to help assemble their abilities, and offer voter and community education and sharpening efforts on gender fairness. It will be very highly important to back gender balance advocates in approaching political gatherings, governments and others to do their part in engaging women. Different activities support young fellows and ladies to take part in supporting around making gender balance measures fundamental to open policy-making. As the UN Women advocates for authoritative and established changes to guarantee women's reasonable access to political circles-as voters, applicants, elected authorities and civil administration individuals. This paper recommends that everyone should also team up with UN nation groups and work with common society on programs so elections maintain and respect women's rights, including to vote and battle free from constituent savagery and violence. Finally, it was noted that the media has turned into convincing organizations of political learning, as youngsters invest a gigantic measure of energy being presented to TVs set, the web, computer games, and other media as opposed to cooperating with live. Media regularly depict adverse messages about political pioneers and government which may prompt the distance of the young ones especially female gender.

\section{References}

Ammerman, N. T. (1987). Bible Believers: Fundamentalists in the Modern World. Rutgers University Press.

Bendroth, Margarot Lamberts. (1993). Fundamentalism and Gender, 1875 to the Present. Yale University Press.

Boundless. (2017). Gender Socialization, sociology - Cochise college boundless, 2016.

Brinkerhoff Merlin, B. \& Marlene, M. M. (1984). Religious Denominations' Impact upon Gender Attitudes: Some Methodological Implications: Review of Religious Research, 25, 365-78.

Brown, Karen. (1994). Fundamentalism and the Control of Women Pp. 175-201 in Fundamentalism and Gender, edited by John Stratton Hawley. Oxford University Press.

Chalfant, H. P., Beckley, R. E. \& Palmer, C. E. (1994). Religion in Contemporary Society.

Dey, I. (2005). Qualitative data analysis. London: Routledge, Taylor and Francis Group.

Ellison Christopher, G. \& Marc Musick, A. (1993). Southern Intolerance: A Fundamentalist Effect? Social Forces, 72, 379-98.

Hawley, J. S. (1994). Fundamentalism and Gender. New York Oxford. Oxford University Press.

Hertel, B. R. \& Michael, H. (1987). Religious Affiliation, Attendance, and Support for 'Pro-Family' Issues in the U.S. Social Forces, 65, 858-82.

Hoffman, J. P. \& Alan, S. M. (1997). Social and Political Attitudes among Religious Groups: Convergence and Divergence over Time: Journal for the Scientific Study of Religion, 36, 52-70.

Huffman Cohen, P. N. \& Pearlman, J. (2010). Engendering Change: Organizational Dynamics and Workplace Gender Desegration, 1975 - 2005. Administrative Science Quarterly, 55(2), 255-277.

Joseph, C. (2002). Gender and Local Government: Occasional Paper (13) S.A: Friedrich Ebert Stiftung.

Kosmin, B. A. \& Lachman, S. (1993). One Nation under God: Religion in Contemporary American Society. Harmony Books. 
Lechner, F. J. (1993). Global fundamentalism, in Swatos WH Jr. (ed) A Future for Religion? New Paradigms for Social Analysis. Newbury Park, 19-36.

Lovenduski, J. (2005). Feminizing Politics. Cambridge: Polity Press.

Martin, P. Y., Marie Withers, O., Hesselbart, S. \& Wood, M. (1980). The Significance of Gender as a Social and Demographic Correlate of Sex Role Attitudes: Sociological Focus, 13, 383-96.

Mason, K. O. \& Yu-Hsia, Lu. (1975). Attitudes toward Women's Familial Roles: Changes in the United States, 1977-1985, Gender and Society, 2, 39-57.

McGuire, M. B. (1981). Religion: The Social Context. Belmont, CA: Wadsworth.

McMurry, M. (1978). Religion and Women's Sex Role Traditionalism. Sociological Focus, 11(2), 81-95.

Mogalakwe, M. (2006). Research Report. The Use of Documentary Research Methods in Social Research. African Sociological Review, 10(1), 221-230.

New Tactics. (2015). Empowering Women in Political Participation and Leadership.

Ramoshaba, W. (2005). Publisher's Note. Portfolio - Municipalities in South Africa in Association with South African Local Government.

Regnerus, M. D., David, S. \& Christian S. (1999). Voting with the Christian Right: Contextual and Individual Patterns of Electoral Influence. Social Forces, 77, 1375.

Smith, K. W. (1974). On Estimating the Reliability of Composite Indexes Through Factor Analysis. Sociological Methods and Research, 2(4), 484-51.

The White Paper. (1998). Local Government document.

Thornton, A. \& Deborah, F. (1979). Changes in Sex-Role Attitudes of Women 1962-1977: Evidence from a Panel Study. American Sociological Review, 44, 831-42.

Thornton, A., Duane, F. A. \& Donald, C. (1983). Causes and Consequences of Sex-Role Attitudes and Attitude Change!' American Sociological Review, 48, 211-27.

UN, women. (2017). Leadership and Political Participation. UN Women USNC Metro NY Chapter.

Vyas-Doorgapersad, S. (2014). Assessing the Role of Gender in Local Governance [Political Context]: The Case of South African Municipalities. OIDA International Journal of Sustainable Development, 07-09.

Wayne, S. (2018). DA and ANC retain competitive seats. Daily Maverick, 12 April 2018.

Williams, S., Seed, J. \& Mwawu, A. (1994). Oxfam Gender Training Manual. Oxford. An Oxfam publication.

Woodberry, R. D. \& Christian, S. S. (1998). Fundamentalism et Al.: Conservative Protestants in America. Annual Review of Sociology, 24, 25-56. 